\title{
Pemanfaatan Manggis Sebagai Sediaan Antiseptik dalam Upaya Peningkatan Kesehatan Masyarakat di Desa Sayang, Jatinangor, Sumedang
}

\author{
Nasrul Wathoni*, ${ }^{*}$, Norisca Aliza Putri ${ }^{1}$, Arief Cahyanto², Muchtaridi ${ }^{3}$
}

\begin{abstract}
${ }^{1}$ Departemen Farmasetika dan Teknologi Farmasi, Fakultas Farmasi, Universitas Padjadjaran, 2Departemen IImu Teknologi dan Material Kedokteran Gigi Fakultas Kedokteran Gigi, Universitas Padjadjaran, ${ }^{3}$ Departemen Analisis Farmasi dan Kimia Medisinal, Fakultas Farmasi, Universitas Padjadjaran,

*E-mail : nasrul@unpad.ac.id

(Submit 12/2/2020, Revisi 12/2/2020, Diterima 13/2/2020)
\end{abstract}

\begin{abstract}
Abstrak
Kuliah Kerja Nyata Mahasiswa (KKNM) merupakan suatu bentuk pengabdian mahasiswa kepada masyarakat, yang mana mahasiswa mengaplikasikan apa yang sudah diterima selama perkuliahan. KKN periode Juni 2019 bersifat terpadu dengan kegiatan Riset dan Pengabdian Pada Masyarakat (PPM) Dosen. Manggis memiliki banyak manfaat bagi kesehatan, salah satunya kandungan Xanthone pada kulit manggis yang berfungsi sebagai antiseptik yang menjadi fokus program kerja KKNPPM ini. Kulit manggis diolah menjadi produk antiseptik yang dapat digunakan secara praktis oleh masyarakat. Produk olahan dari kulit manggis berupa Sabun Cair Antiseptik dan Gel Antiseptik. Setelah kegiatan KKN-PPM ini berakhir, pengetahuan masyarakat tentang pengolahan buah atau tumbuhan sebagai produk yang bermanfaat bagi kebersihan dan kesehatan, khususnya buah manggis, diharapkan dapat bertambah.setelah dilakukannya penyuluhan mengenai betapa pentingnya menjaga kesehatan terutama pada hal mencuci tangan dengan benar maka dengan begitu tingkat kesehatan masyarakat akan meningkat seiring dengan peningkatan kesejahteraan ekonomi masyarakat. Setelah dilakukan penyuluhan tentang manfaat buah manggis kami mendapati bahwa pengetahuan masyarakat tentang manggis meningkat, khususnya pada pengetahuan tentang manfaat buah manggis yang saat pre-test sebanyak $76.92 \%$ menjawab benar kemudian saat post-test meningkat menjadi $84.61 \%$. Berdasarkan pre-test dan post-test yang kami lakukan juga dapat disimpulkan pengetahuan masyarakat tentang buah manggis dapat diolah menjadi produk antiseptic juga meningkat, dimana saat pre-test $76.92 \%$ menjawab benar dan setelah post-test $\quad 100 \%$ menjawab benar. Kemudian setelah dilakukan praktek langsung membuat gel antiseptic bersama masyarakat, berdasarkan post-test kami mendapati bahwa $46.15 \%$ masyarakat sangat tertarik dan $23.03 \%$ tertarik dengan gel antiseptic.
\end{abstract}

Kata kunci: Manggis, Desa Sayang, Sabun Cair Antiseptik, Gel Antiseptik 


\section{Outline}

- Pendahuluan

- Metode

- Hasil dan Pembahasan

- Kesimpulan

- Ucapan Terimakasih

- Daftar Pustaka

\section{Pendahuluan}

Kuliah Kerja Nyata Mahasiswa (KKNM) merupakan suatu program Universitas Padjadjaran sebagai salah satu implementasi Tri Dharma Perguruan Tinggi yaitu pengabdian kepada masyarakat dengan membantu masyarakat mengembangkan potensi yang ada pada masyarakat. Mahasiswa mengaplikasikan ilmu yang didapat dari bangku perkuliahan secara langsung kepada masyarakat dengan cara membimbing dan mendorong masyarakat memanfaatkan sumber daya yang ada sehingga memberikan manfaat bagi masyarakat. Program ini dilaksanakan dengan menyelaraskan kegiatan Riset dan Pengabdian Pada Masyarakat (PPM) dari Dosen dengan mahasiswa lintas keilmuan.

KKN menjadi sarana bagi mahasiswa untuk dalam mengaplikasikan ilmunya secara nyata sehingga dapat memberikan manfaat dan nilai secara langsung kepada masyarakat dan pemerintah Desa. Mahasiswa juga turut andil dalam membantu masyarakat dalam memecahkan masalah yang ada dalam masyarakat dengan program yang dijalankan.

Kuliah Kerja Nyata Mahasiswa periode Juli 2019 ini bertempat di Desa Sayang, Kecamatan Jatinangor, Kabupaten Sumedang dengan topik 'Pemanfaatan Manggis sebagai sediaan antiseptik dalam upaya peningkatan kesehatan masyarakat' . Antiseptik atau germisida adalah senyawa kimia yang digunakan untuk membunuh atau menghambat pertumbuhan mikroorganisme pada jaringan yang hidup seperti pada permukaan kulit dan membran mukosa. Antiseptik dapat ditemukan dalam kandungan buah seperti buah manggis, dimana kulit buah manggis mengandung zat Xanthone yang berfungsi sebagai antiseptik atau anti bakteri.

Kesehatan merupakan hal yang sangat penting dan berharga untuk dijaga agar meningkatkan produktivitas dan kesejahteraan. Dalam menjaga kesehatan kita perlu memelihara kebersihan tangan. Karena pada saat melakukan aktivitas sehari-hari tangan seringkali terkontaminasi bakteri, dan melalui tangan bakteri dapat masuk ke dalam tubuh. Kebersihan merupakan hal yang sangat penting karena semakin banyaknya penyakit yang timbul karena bakteri dan kuman ${ }^{1}$. Salah satu cara memelihara kebersihan tangan adalah dengan membiasakan diri mencuci tangan dengan sabun. Sabun merupakan hasil hidrolisa asam lemak dan basa ${ }^{2}$. Peristiwa ini dikenal dengan peristiwa saponifikasi. Saponifikasi adalah proses penyabunan yang mereaksikan suatu lemak atau gliserida dengan basa. Manggis (Garcinia mangostana L.) merupakan tanaman tahunan yang hidup di daerah tropis, buahnya memiliki rasa manis dan sedikit masam ${ }^{3}$. 
Kulit buah manggis mempunyai sifat sebagai antiaging, menurunkan tekanan darah tinggi, menurunkan berat badan, antivirus juga antibakteri ${ }^{4}$. Jumlah produksi manggis di Indonesia mencapai 190,294 ton ${ }^{5}$. Hal ini memudahkan masyarakat untuk memanfaatkan manggis sebagai antiseptik dengan mengolahnya sendiri. Masyarakat dapat mengkonsumsi buah manggis dan kulitnya diolah menjadi antiseptik yang siap digunakan.

Hal inilah yang menjadi fokus KKN ini dimana mahasiswa memberikan pengetahuan kepada masyarakat tentang cara mengolah kulit manggis menjadi sabun cair atau gel hand sanitizer yang dapat digunakan sehari-hari dan memberikan pengetahuan akan pentingnya budaya cuci tangan guna meningkatkan kesehatan di masyarakat.

\section{Metode}

Pengabdian pada masyarakat dilaksanakan dengan metode Pendampingan Partisipatif, yaitu masyarakat dilibatkan dalam pelaksanaan kegiatan pengabdian kepada masyarakat pada suatu lokasi/kelompok. Pelaksanaan KKNM-PPM 2019 dimulai dari kegiatan pembekalan oleh Dosen Pembimbing Lapangan (DPL), Survei ke Desa Sayang, Pembuatan contoh produk untuk PKM yakni terdiri dari sabun cair dan gel hand sanitizer.

\section{Hasil dan Pembahasan}

Desa Sayang merupakan sebuah desa yang berada di Kecamatan Jatinangor Kabupaten Sumedang. Lokasinya berada di bagian tengah wilayah kecamatan dan memanjang ke bagian selatan berbatasan dengan Kabupaten Bandung. Secara administratif, Desa Sayang dibagi ke dalam tiga wilayah dusun yaitu Dusun 1, Dusun 2 dan Dusun 3. Sementara Jumlah wilayah Rukun Warga dan Rukun Tetangga masingmasing sebanyak $13 \mathrm{RW}$ dan $48 \mathrm{RT}^{6}$. Seluruh RW Desa Sayang ini terlibat dalam pelaksanaan KKNM demi terwujudnya peningkatan kesehatan masyarakat Desa Sayang.

Pelaksanaan KKNM dilakukan dengan mengadakan kegiatan sosialisasi mengenai pemanfaatan kulit manggis sebagai sabun cair dan gel antiseptik. Kegiatan ini dilakukan di aula kantor desa Sayang dan dihadiri oleh 52 orang masyarakat Desa Sayang. Selain itu juga dilakukan demo mengenai pembuatan gel antiseptik agar masyarakat dapat mempraktikan kembali di rumah bagaimana cara membuat gel antiseptik dengan sederhana. Masyarakat Desa Sayang terlihat antusias ketika melakukan demo pembuatan gel antiseptik.

Hasil capaian dari kegiatan $\mathrm{KKN}$ ini adalah untuk mengetahui seberapa besar pengetahuan masyarakat Desa Sayang mengenai manfaat kulit manggis yang umumnya dijadikan limbah. Untuk mengetahuinya kami menggunakan metode Pre-Post Test yang dilaksanakan ketika kegiatan sosialisasi berlangsung. Dengan sasaran responden yaitu masyarakat berjenis kelamin wanita dalam pengisian pre dan post test kami. Berikut hasil pre test yang telah didapatkan mengenai manggis serta pemanfaatannya sebelum dilakukannya sosialisasi pada tabel 1. 
Tabel 1. Hasil Persentase Pre-Test Pengetahuan Masyarakat Desa Sayang Mengenai Manggis dan Manfaatnya

\begin{tabular}{|c|c|c|c|}
\hline NO & PERTANYAAN & BENAR (\%) & SALAH (\%) \\
\hline 1 & Asal buah manggis & $100 \%$ & - \\
\hline 2 & Manggis tumbuh di iklim & $81.82 \%$ & $15.38 \%$ \\
\hline 3 & Ciri bauh manggis yang segar & $68.75 \%$ & $38.46 \%$ \\
\hline 4 & Ciri buah manggis yang matang & $76.92 \%$ & $23.07 \%$ \\
\hline 5 & Manfaat buah manggis & $76.92 \%$ & $23.07 \%$ \\
\hline 6 & $\begin{array}{l}\text { Sebagai antibakteri ,buah manggis dapat diolah } \\
\text { menjadi apa }\end{array}$ & $76.92 \%$ & $23.07 \%$ \\
\hline 7 & Bagian manggis yang diolah menjadi sabun manggis & $100 \%$ & - \\
\hline 8 & Julukan manggis & $53.84 \%$ & $46.15 \%$ \\
\hline 9 & Bukan fungsi xanthone & $84.61 \%$ & $15.38 \%$ \\
\hline
\end{tabular}

Berdasarkan hasil pre-test, semua responden sejumlah 52 orang $(100 \%)$ mengetahui benua asal tumbuhnya buah manggis. Sedangkan sebanyak $18,18 \%$ masyarakat kurang mengetahui mengenai iklim dimana buah manggis dapat tumbuh. Pengetahuan masyarakat mengenai kriteria buah manggis yang segar tergolong cukup baik yaitu $68,75 \%$ dimana buah manggis yang segar kulitnya akan terasa empuk bila ditekan. Sebanyak $76,92 \%$ mengetahui warna kulit manggis yang sudah matang, manfaat dari kulit manggis yaitu sebagai antioksidan dan antibakteri ${ }^{7}$, serta mengetahui pengolahan dari manggis yaitu dapat diolah menjadi sabun cuci tangan. Pengetahuan masyarakat mengenai bagian buah manggis yang dapat dimanfaatkan sebagai sabun sudah sangat baik karena semua responden menjawab benar. Sebanyak 53,84\% dari masyarakat mengetahui julukan buah manggis yaitu dikenal sebagai ratu buah karena memiliki kandungan Xanthone. Pengetahuan masyarakat mengenai fungsi dari kandungan kulit manggis berupa xanthone sangat baik karena sebanyak $84,61 \%$ menjawab dengan benar. Berdasarkan hasil pre-test, seluruh masyarakat belum pernah mencoba produk sabun manggis dan sebanyak $46,15 \%$ tertarik akan produk sabun manggis, sedangkan sebanyak $23,3 \%$ menyatakan sangat tertarik terhadap sabun manggis. Sebanyak $53,84 \%$ dari masyarakat mengetahui kepanjangan dari MASAMA, yaitu mandi sabun manggis.

Tabel 2. Hasil Persentase Post-Test Pengetahuan Masyarakat Desa Sayang Mengenai Manggis dan Manfaatnya

\begin{tabular}{|c|c|c|c|}
\hline NO & PERTANYAAN & BENAR (\%) & SALAH (\%) \\
\hline 1 & Asal buah manggis & $100 \%$ & - \\
\hline 2 & Manggis tumbuh di iklim & $100 \%$ & - \\
\hline 3 & Ciri buah manggis yang segar & $76.92 \%$ & $23.07 \%$ \\
\hline 4 & Ciri buah manggis yang matang & $84.61 \%$ & $15.38 \%$ \\
\hline 5 & Manfaat buah manggis & $84.61 \%$ & $15.38 \%$ \\
\hline 6 & $\begin{array}{l}\text { Sebagai antibakteri , buah manggis dapat diolah } \\
\text { menjadi apa }\end{array}$ & $100 \%$ & - \\
\hline 7 & Bagian manggis yang diolah menjadi sabun manggis & $100 \%$ & - \\
\hline 8 & Julukan manggis & $76.92 \%$ & $23.07 \%$ \\
\hline 9 & Bukan fungsi xanthone & $100 \%$ & - \\
\hline
\end{tabular}


Tabel 3. Pertanyaan Produk

\begin{tabular}{|c|c|c|c|c|}
\hline NO & PERTANYAAN & \multicolumn{3}{|c|}{ TANGGAPAN } \\
\hline \multirow[t]{3}{*}{1} & \multirow{3}{*}{$\begin{array}{l}\text { Sudah coba } \\
\text { produk sabun } \\
\text { manggis }\end{array}$} & \multirow[t]{2}{*}{ SUDAH } & \multirow[t]{2}{*}{ BELUM } & TIDAK \\
\hline & & & & INGAT \\
\hline & & - & $100 \%$ & - \\
\hline \multirow[t]{3}{*}{2} & \multirow{3}{*}{$\begin{array}{l}\text { Tertarik pada } \\
\text { sabun manggis }\end{array}$} & SANGAT & TERTARIK & BIASA \\
\hline & & TERTARIK & & SAJA \\
\hline & & $46.15 \%$ & $23.03 \%$ & $30.70 \%$ \\
\hline \multirow[t]{4}{*}{3} & \multirow{4}{*}{$\begin{array}{l}\text { Kepanjangan } \\
\text { MASAMA }\end{array}$} & MANGGIS & MANGGIS & MANDI \\
\hline & & SAMPAI & SABUN & SABUN \\
\hline & & MATI & MANGGIS & MANGGIS \\
\hline & & - & $46.15 \%$ & $53.84 \%$ \\
\hline \multirow[t]{3}{*}{4} & \multirow{3}{*}{$\begin{array}{l}\text { Tingkat } \\
\text { keharuman } \\
\text { produk }\end{array}$} & SANGAT & SETUJU & TIDAK \\
\hline & & SETUJU & & SETUJU \\
\hline & & $53.84 \%$ & $46.15 \%$ & - \\
\hline \multirow[t]{3}{*}{5} & \multirow{3}{*}{$\begin{array}{l}\text { Efektif } \\
\text { membersihkan } \\
\text { tangan }\end{array}$} & SANGAT & SETUJU & TIDAK \\
\hline & & SETUJU & & SETUJU \\
\hline & & $30.76 \%$ & $69.23 \%$ & - \\
\hline \multirow[t]{3}{*}{6} & \multirow{3}{*}{$\begin{array}{l}\text { Tekstur produk } \\
\text { saat } \\
\text { diaplikasikan }\end{array}$} & SANGAT & \multirow[t]{2}{*}{ SETUJU } & TIDAK \\
\hline & & SETUJU & & SETUJU \\
\hline & & $23.03 \%$ & $76.92 \%$ & - \\
\hline
\end{tabular}

Setelah dilaksanakan sosialisasi mengenai materi pemanfaatan kulit manggis sebagai sediaan antiseptik, dilakukan penilaian kembali terhadap pengetahuan masyarakat dengan pemberian post-test. Berdasarkan hasil post-test, semua masyarakat mengetahui asal buah manggis yaitu berasal dari benua Asia dan juga masyarakat mengetahui bahwa manggis tumbuh di ilkim tropis. Terjadi peningkatan sebesar $7,97 \%$ mengenai pengetahuan ciri-ciri buah manggis yang segar, dimana ciri-ciri buah manggis yang segar adalah kulit buah terasa empuk apabila ditekan. Pengetahuan masyarakat mengenai kriteria warna kulit manggis yang telah matang juga mengalami peningkatan sebesar 7,69\%. Namun, setelah dilakukannya pemberian materi masih terdapat $15,39 \%$ dari total masyarakat yang menjawab salah mengenai manfaat buah manggis. Semua masyarakat yang berpartisipasi sudah mengetahui bahwa kulit manggis dapat dimanfaatkan sebagai sabun cuci tangan. Terjadi peningkatan persentase yang cukup signifikan mengenai julukan buah manggis yaitu meningkat sebanyak $25,36 \%$. Dari yang sebelumnya masyarakat tidak mengetahui fungsi dari Xanthone, setelah pemberian materi semua masyarakat jadi mengetahui fungsi Xanthone yaitu sebagai antioksidan dan antibakteri. Antusiasme masyarakat terhadap produk sabun manggis meningkat terlihat dari persentase yang menyatakan sangat tertarik terhadap sabun manggis mengalami peningkatan menjadi $38,46 \%$. Masyarakat juga menjadi lebih tau mengenai kepanjangan dari MASAMA setelah diberikan materi.

Mengenai tanggapan produk sabun manggis, $53,84 \%$ dari 52 responden menyatakan produk sabun manggis memiliki bau yang harum. Sebanyak $69,23 \%$ dari 52 responden menyatakan sangat setuju bahwa produk sabun manggis dapat membersihkan kulit. Dan $76,92 \%$ dari 52 responden menyatakan sangat setuju bahwa tekstur dari produk sabun manggis nyaman digunakan di kulit. 
Berdasarkan hasil sosialisasi dan juga pelaksanaan pre-post test dinyatakan bahwa pengetahuan masyarakat mengetahui manggis, manfaat buah dan kulitnya serta pemanfaatan kulit manggis menjadi produk sabun manggis dinyatakan mengalami peningkatan dari sebelumnya. Diharapkan dengan adanya kegiatan KKNM mengenai pemanfaatan kulit manggis sebagai antiseptik ini dapat meningkatkan kesadaran masyarakat mengenai pentingnya menjaga kebersihan serta diharapkan dengan adanya produk sabun manggis antiseptik ini dapat meningkatkan kesehatan masyarakat Desa Sayang.

\section{Kesimpulan}

Dari hasil pre-test yang kami berikan sebelum pemberian materi dan post-test setelah pemberian materi serta praktek membuat gel antispetik kami menyimpulkan bahwa pengetahuan masyarakat tentang manfaat dari buah manggis sebagai antiseptik meningkat dari sebelum dilakukannya penyuluhan. Sehingga dari kegiatan KKN Desa Sayang 2019 yang telah dilaksanakan ini, diharapkan masyarakat di Desa Sayang mampu memanfaatkan hasil perkebunan untuk diubah menjadi suatu produk yang mempunyai nilai lebih seperti gel antiseptik yang berbahan dasar kulit manggis yang banyak mengandung komponen bahan aktif Xanthone. Kulit manggis yang mengandung Xanthone tersebut dapat diolah menjadi sediaan antiseptik seperti sabun cair antiseptik dan gel antiseptik.

\section{Ucapan Terimakasih}

Ucapan terimakasih kepada tim KKN mahasiswa Desa Sayang yakni Kintan Ratusyahtika Virdauzy, Alya Maesha, Lady Andra Netta Pardede, Farah Nurhabibah, Gita Mulyani, Prihatur Setyo Putra, Muhammad Fajrul Rahman, Dega Bagaskara, dan Sandra Restuti Febriana yang telah menyelesaikan program KKN PPM dosen dengan baik.

\section{Daftar Pustaka}

1. Yunia Irmayanti, P., Ayu Dewi Wijayanti, N., \& Istri Sri Arisanti, C. (2014). OPTIMASI FORMULA SEDIAAN SABUN MANDI CAIR DARI EKSTRAK KULIT MANGGIS (Garcinia Mangostana Linn.). Jurnal Kimia (Journal Of Chemistry), . Retrieved from https://ojs.unud.ac.id/index.php/jchem/article/view/11765

2. Srihari E, Lingganingrum F S. 2015. Ekstrak Kulit Manggis Bubuk. Jurnal Teknik Kimia. 1:1-7

3. Muchtaridi, Nurhidayah W, Setyawati L, Rochdian D, Islamiaty, Budiman A. 2019. Pendekatan Sosio-Ekonomi Potensi Daerah sebagai Pusat Ekstrak Kulit Manggis di Indonesia. Jurnal Pengabdian Kepada Masyarakat. 2:179-188

4. Meilina N, Hasanah A. 2018. Review Artikel:Aktivitas Antibakteri Ekstrak Kulit Buah Manggis (Garcinia mangostana L) Terhadap Bakteri Penyebab Jerawat. Farmaka. 2:322-328

5. Praptiwi M. 2010. Uji Aktivitas Antibakteri Ekstrak Kulit Buah Manggis (Garcinia mangostana Linn). Media Litbang Kesehatan. 2:65-69 
6. Sari t, Kasih J, Sari T. 2010. Pembuatan Sabun Padat Dan Sabun Cair Dari Minyak Jarak. Jurnal Teknik Kimia. 1:28-33

7. Gusviputri A, Meliana N, Aylianawati, Indraswati N. 2013. Pembuatan Sabun Dengan Lidah Buaya (Aloe Vera) Sebagai Antiseptik Alami. Widya Teknik. 1:11-21

8. Immanudin A. 2017. Desa Sayang. Tersedia pada http://sumedangtandang.com/direktori/detail/desa-sayang.htm 